\title{
Evolving role of radiotracers in coastal zone studies is
}

\author{
Peter Airey ${ }^{\mathrm{a}, *}$, Cath Hughes ${ }^{\mathrm{a}}$, Thomas Kluss ${ }^{\mathrm{a}}$, Emerenciana Duran ${ }^{\mathrm{b}}$, Brett Miller ${ }^{\mathrm{c}}$, \\ Siripone Chiuenta ${ }^{\mathrm{d}}$, Alexander F. Nielsen ${ }^{\mathrm{e}}$, Suzanne Hollins ${ }^{\mathrm{a}}$ \\ ${ }^{a}$ Australian Nuclear Science and Technology Organisation, Menai, NSW 2234, Australia \\ ${ }^{\mathrm{b}}$ Philippines Nuclear Research Institute, Quezon City, Philippines \\ ${ }^{\mathrm{c}}$ Water Research Laboratory, University of New South Wales, Manly Vale, NSW, Australia \\ ${ }^{\mathrm{d}}$ Office of Atomic Energy for Peace, Chatuchak district, Bangkok, Thailand \\ ${ }^{\mathrm{e}}$ Snowy Mountains Engineering Corporation, North Sydney NSW 2509, Australia
}

Received 16 October 2002; accepted 16 November 2002

\begin{abstract}
Recent advances in the off-shore radiotracing program in the Asia Pacific region are described with examples from the Philippines, Thailand, Hong Kong and Australia. Advances are driven by changing requirements from the user community which include: (1) the need to experimentally evaluate the output of numerical models underpinning engineering and environmental investigations; (2) the need to address increasingly sophisticated questions posed by researchers into coastal ecosystems; and (3) the need to respond to pressures from regulators to minimise the level of tracer released to the environment. Four stages in the recent evolution of tracer technology are identified.
\end{abstract}

Crown Copyright (C) 2003 Published by Elsevier Science Ltd. All rights reserved.

Keywords: Radiotracing; Bedload transport; Contaminant transport; Sewage transport; Cohesive sediment transport

\section{Introduction}

Sustainable development of the coastal zones is the key to the on-going well-being of many of the world's peoples. Integrated coastal zone management is necessary to meet the challenges of economic development while also addressing the consequences of the past overexploitation of environmental resources and the future impacts of climate change. For instance, decision makers may need to balance the requirements of the fishing and tourist industries for a pristine environment with the demands from coastal cities for access to the sea for sewage and industrial effluent disposal.

Physical as well as socio-economic models are essential management tools. The former include fluid dynamic models of contaminant and bed-load transport. Evalua-

\footnotetext{
This paper was presented at the 4th International Conference on Isotopes held in Cape Town, South Africa from 10-14 March 2002.

*Corresponding author. Fax: +61-2-9717-9260.
}

tion using tracer techniques greatly enhances confidence in the predictive value of such models. Indeed, tracing and numerical modelling are complementary methods of studying complex environmental systems. Tracer data are based on direct observation but are limited to the labelled component of the system and to a restricted domain of space and time. Numerical models can in theory accommodate all the important parameters, but are limited by their underlying assumptions and accessible computing power. Separately, both approaches have limitations, but together they offer a very powerful method of investigating a complex environment.

If tracer applications were limited to model evaluation they would be useful to decision makers, but of limited research interest. Over the past few years it has become clear that the synergistic modelling and tracer approach can make a significant contribution to addressing questions at the limit of our current knowledge. A discussion of case studies underpinning these assertions and comments on the evolving frontier in off-shore radiotracing are the themes of this paper. 


\section{Case studies}

Case studies are here classified according to their impact on the evolution of modern off-shore radiotracing. Four overlapping stages can be identified.

- The first stage is associated with the use of tracers to evaluate numerical transport models. Previously, radiotracing was seen primarily as a useful source of independent information on transport processes. The current focus on model evaluation reflects a paradigm shift in the approach to tracer applications (Airey et al., 2001).

- The second stage involves the use of hydrodynamic models to optimise the design of tracer studies. Numerical modelling and the experimental evaluation of the models are becoming iterative processes.

- The third stage in the evolution of radiotracing reflects the much wider and more sophisticated applications made possible by integration of the tracer and modelling approaches to coastal investigations.

- The fourth stage is derived from the third and reflects the role of the integrated approach in addressing research questions at the limit of current knowledge.

\subsection{Stage 1: evaluation of contaminant transport models}

ANSTO has been associated with the Water Research Laboratory of the University of New South Wales (WRL) in a number of post-commissioning trials of new or up-graded ocean sewage outfalls in Sydney (Pritchard et al., 1993) and Hong Kong (Hughes et al., 2000). Both series of investigations involved the evaluation of the RMA suite of hydrodynamic models (King, 1993). These models were then used to predict the fate and behaviour of sewage effluent with greatly enhanced confidence. In the former case, the evaluated models use automated data from the Ocean Reference Station off Sydney to describe the behaviour of the effluent from each of the ocean outfalls at any time.

An investigation at the Malabar (Sydney) outfall, which discharges sewage into the ocean at $80 \mathrm{~m}$ depth some $4 \mathrm{~km}$ off shore, will also be used to illustrate the versatility of the tracer approach. Radioactive plumes were tracked in a southerly direction for distances up to $35 \mathrm{~km}$ from the point of release using the mixed tracer gold-198/tritium (HTO) tracer. The levels of bacteria from the labelled sewage were measured, the results corrected for dilution and a true 'die off' rate was calculated for the bacteria in the ocean. An effective half-life of about $8 \mathrm{~h}$ was estimated. In a related investigation a surrogate for sewage grease was labelled with tritiated vegetable oil and its dispersion monitored.

\subsection{Stage 2: role of transport models in the design of the tracer study}

The concept of the tracer study is self-evident where the source term is well defined as in the dispersion of contaminants from engineered outfalls. However, the experimental evaluation of more general regional transport models presents greater challenges. The number of tracer studies that can be undertaken is extremely limited, and for optimum results, the injection points should be chosen at locations where the model output is particularly sensitive to the choice of input parameters. These may be identified through earlier runs of the model, in which case the refinement of the model and its experimental evaluation are on-going interactive processes.

For example, an investigation was recently undertaken of sand transport in the vicinity of the Port of Songkhla on the southern gulf coast of Thailand (Nielsen et al., 2001). The project was supported by the IAEA RCA and undertaken by the following organisations: Office of Atomic Energy for Peace, Thailand (OAEP), ANSTO, the Thai Harbour Authority, the Prince of Songkhla University, and the UNSW Water Research Laboratory.

The outcome of the project was a bed-load transport model designed to underpin decisions on Port development. An evaluation study extending over six weeks during the monsoon season using iridium-192 labelled sand particles (half-life 74 days) was implemented.

Optimising the locations of tracer injection presented a serious problem as most of the domain was dominated by reversing tidal currents where the observed transport of the tracer over a tidal cycle would be the small net difference between two large effects. Under these conditions, the tracer data would have been of limited use in model evaluation. However, the tidal hydrodynamic model showed that there were two coastal locations influenced by the outflow of the Songkhla Lake where the current directions during the ebb tide and the flood tide were similar (Fig. 1). These were chosen as the injection sites.

Radiotracer and model results are shown in Fig. 2. Estimates of net bed-load transport from the radiotracer data are expressed as mass per metre of transect normal to the average direction and were calculated from the displacement the tracer centroid during the period of observation (25 November 1999-7 January 2000). They are shown by the lengths and directions of the arrows and agree well with the modelled data calculated from the weighted mean values making up the sediment roses (Nielsen et al., 2001). While modelling gives insights into the complexities of the transport processes, the radiotracer data are extremely useful as they are based on direct observation of the sand migration in nature. 

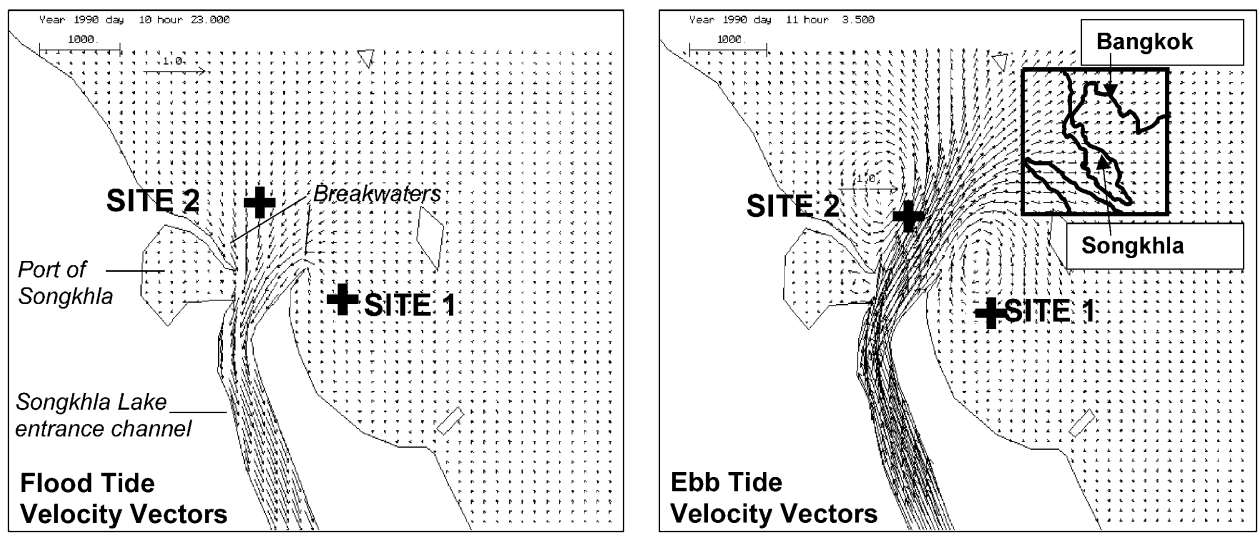

Fig. 1. Flood and ebb tide modelled velocities for the Port of Songkhla area. Ebb tide eddy circulation patterns adjacent to the channel outlet result in net movement towards the channel. Radiotracer study sites 1 and 2 are shown (after Nielsen et al., 2001).

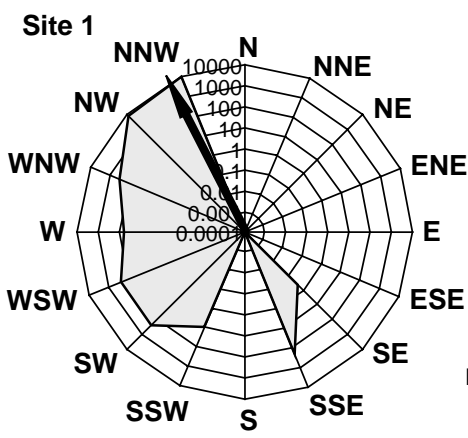

Nett Transport $=16560 \mathrm{~kg} / \mathrm{m} @ 321^{\circ}$
Site 2

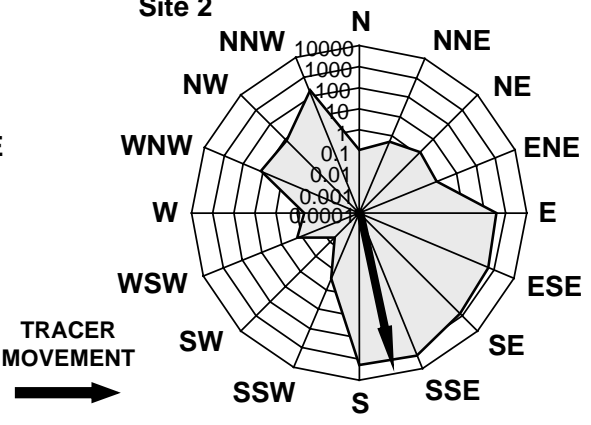

Nett Transport $=4337 \mathrm{~kg} / \mathrm{m} @ 162^{\circ}$

Fig. 2. Sediment transport roses for Songkhla study sites 1 and 2. For the period 25 November 1999 to 7 January 2000 modelled transport (shaded area) compares well with estimates derived radiotracer data (arrow).

\subsection{Stage 3: scientific return from aligning tracer studies with numerical modelling}

The broadening of the concept of the tracer study from an independent source of information to a means of evaluating multi-parameter models has led to very substantial scientific returns. This is because a much wider range of practical questions may thereby be addressed quantitatively. Two examples will be presented: (a) an investigation of the relative effects of wind fields and currents on the dispersion of contaminants in the water column and (b) an attempt to quantify the relative impacts of normal conditions and major storm events on beach erosion and sand dynamics.

(a) The effect of wind fields on contaminant dispersion: The Philippines Nuclear Research Institute (PNRI) and ANSTO recently undertook a tracer study to evaluate a three-dimensional hydrodynamic and water quality model of Manila Bay developed by the UNSW
Water Research Laboratory (Miller et al., 2001). The project was supported by the IAEA and was undertaken in collaboration with the Philippines Department of Fisheries and the Philippines Navy. The aim was to provide a tool that could contribute to the understanding of nutrient flows leading to recurrent harmful algal blooms in the bay. The tracer injections were undertaken on 4 and 5 December 2000 with technetium$99 \mathrm{~m}$ eluted from a medical generator. The isotope was injected near the entrance of Manila Bay in the North Channel about $8 \mathrm{~km}$ from Corregidor Island. The results are set out in the reference.

The model output clearly showed that the wind field was the dominating factor determining contaminant transport. The tracer studies were essential in obtaining actual dispersion and dilution data under prevailing wind conditions to feed into the model. The model and tracer results both showed significant vertical stratification with winds dominating surface flows and tidal reversing flows with depth. 
(b) The effect of storm events of beach dynamics: Recent advances in position fixing and in the processing of data have resulted in greatly enhanced precision with which the transport and redistribution of sand and sediments can be monitored. The impact of storms on beach dynamics can be studied by monitoring the distribution of the radioisotope labelled sand before and after the event.

For instance, ANSTO is involved with the Coastal Studies Unit of the University of Sydney and the NSW Department of Land and Water Conservation in such a study at MacMasters Beach on the NSW Central Coast north of Sydney. The immediate aim is to improve the understanding of the formation of mega-rips resulting from bay-scale circulation patterns which are believed to be responsible for the removal of sand from the beach zone during storm events. The longer-term aim is to evaluate models designed to assess the impact of climate change scenarios on beach processes.

Iridium-192 labelled glass "sand" (half-life 74 days) of a pre-chosen particle size distribution was injected at four locations of different depths at the instrumented reference site. Injections were made in February 2001, and observations made for a year following injection. During the study, a number of storm periods were experienced with a major storm in late July 2001. In one location, the tracer was transported a significant distance and subsequently dispersed, and in the others there is evidence that the tracer was buried during the July 2001 storm. A coring program has been undertaken to study the incorporation of the labelled surface sand into the profile.

\subsection{Stage 4: use of tracers to address questions at the limit of current knowledge}

The application of radiotracer techniques to environmental engineering dates back to the 1940s. The resilience of the technique is demonstrated by the fact that six decades later, radiotracing is still contributing to major research issues. Two examples will be cited.

\subsubsection{Fate and behaviour of sewage particles: a field investigation}

There is increasing interest in the fate and behaviour of particles released to the coastal zone from off-shore sewage outfalls. For instance, an investigation was undertaken at the Burwood Beach outfall near Newcastle NSW (Airey et al., 1999). The aims of the investigation were: (1) to model the processes of particle aggregation and de-flocculation and to evaluate the model with laboratory studies; and (2) to investigate the fate and behaviour the sewage particles in the field.

The tracers gold-198 and tritiated water HTO were used to ensure that the samples taken were of diluted sewage released through the outfall during the time of the injection. Samples within the plume were collected, split and returned to the laboratory. Accurately measured tritium levels were used to monitor the increasing dilution as the effluent dispersed into the sea. The remaining sample was used to study the properties of the particles; namely the particle size distributions and the fractal dimensions (Zaw et al., 1999).

The most definitive data were obtained in a study on 28 May 1998. It was found that the particle sizes generally increased with increasing distance from the outfall. At the same time the fractal dimension that correlates inversely with porosity was found to decrease. It would appear that the enhanced aggregation is accompanied by enhanced porosity. The entrapped sewage water is relatively less dense than the surrounding sea water. The particles are therefore subject to buoyancy, which is consistent with the observation that sewage particles often rise through the water column to the near surface region. A particle aggregation model has been developed and validated using laboratory data. Further work is needed in this area.

\subsubsection{New fields of application; cohesive sediment (mud) transport}

Major gaps in our understanding of the transport of cohesive sediments in ports and estuaries have been brought to light by a major E.U. funded research programme carried out between 1997 and 2000 on the "Prediction of Cohesive Sediment Transport and Bed Dynamics in Estuaries and Coastal Zones with Integrated Numerical Simulation Models (COSINUS)". A succinct statement of the current state of this knowledge is available at http://www.kuleuven.ac.be/bwk/cosinus/ cst.htm.

The European participants used a combination of process modelling and sophisticated field and laboratory observations. Tracer and related nuclear techniques also have a great deal to offer. Two of the three gaps in knowledge identified in the Final Report are:

1. A tractable model of history effects on flocculation and floc break-up in turbulent flow is needed.

2. A physically based bed erosion model is required which takes into account the interaction between the turbulence and the soil-mechanical properties of the bed.

Some work in this area was discussed above. Two approaches are being taken to address the second topic. Firstly, a long-term study of the mobility of cohesive sediment in Homebush Bay within Sydney Harbour has commenced. The redistribution of the tracer will be interpreted in terms of a hydrodynamic model of the area and the properties of the bed. Secondly, an innovative nucleonic device is being constructed to 
monitor changes in bulk density (i.e. porosity) up to $50 \mathrm{~cm}$ below the surface of the mud or sand. The observed impact of currents on the bulk density profiles will provide important clues to the mechanism of bedload transport.

\section{Future challenges}

Radiotracer investigations are implemented in an increasingly regulated environment where alternative technologies are usually favoured. This has two consequences. Firstly, new applications are being sought in areas where nuclear techniques can make an uncontested contribution to coastal studies. Examples were presented in the previous section. Secondly, an on-going program of technology development is being progressed to enhance the quality of information that can be obtained from ever decreasing levels of tracer. Success will provide a platform for moving beyond evaluation to the greater challenge of model validation and extension.

\subsection{Innovative and improved technology}

The aims of technology development are to extend the range of measurements that can be made and to enhance the quality of information obtained from decreasing levels of injected tracer. An example of the former is presented above. The latter is achieved through the process of continuous improvement.

ANSTO has been working with a local company Bruttour International in developing off-shore tracer capabilities. Accurate position fixing capability is now linked to the radiation monitors, and devices to monitor the depth of the detectors and, in the case of bed-load transport, the direction and the declination of the towing cable are being developed. The multiplexing unit Ceeplexer ${ }^{\circledR}$ generates the data as a single string and a software interface to allow real time data visualisation which allows adjustments in data collection strategy is in development.

The choice of tracer is often crucial to the success of a study. In the Manila Bay investigation discussed above, a $400 \mathrm{GBq}$ Gentech ${ }^{\circledR}$ technetium-99m generator was used. This had operational and regulatory advantages over other open sources. We are now at the stage where significant coastal investigations can be undertaken with a medical generator and precise, compact navigation and monitoring equipment.

\subsection{Model validation}

One of the challenges for the future is to move tracer techniques towards the validation of numerical trans- port models as opposed to the less exacting task of evaluation.

At present, most tracer studies of contaminant transport in the water column focus on measuring dilution factors as well as dispersion coefficients in three dimensions. The process of moving towards model validation involves reducing the numbers of degrees of freedom in setting parameter values still further. As a step in this direction, ANSTO is planning to attempt to use tracers for a direct measurement of hydrodynamic shear stress.

\section{Concluding comment}

Mention was made above to a shifting in the concept of off-shore tracer studies from an independent means of obtaining information to a means of evaluating the output of multi-parameter models. If this shift heralded the modern age of off-shore radiotracing, we may now be entering a post-modern period, where nuclear related data are applied not only to evaluation but increasingly to model validation and extension. Questions at the limits of scientific knowledge are being addressed.

\section{References}

Airey, P., Zaw, M., Szymczak, R., Kluss, T., Jiyuan, Tu., Barry, J., 1999. Application of radiotracer techniques to the validation of contaminant transport models at sewage outfall. Proceedings of the Conference Paper 145 Global 99, Jackson Hole Wyoming, August 1999.

Airey, P., Hughes, C., Hollins, S, Kluss, T., 2001. The evolving role of radiotracing in integrated coastal zone management investigations. In; Ramanmoorthy, N., Ananthakrishnan, M., Nandakumar, A.N. (Eds.), Proceedings of the NAARRI International Conference on the Applications of Radiation and Radiation Technology in the 21st Century December 2001 National Association for the Applications of Applied Radiation and Isotopes in Industry, Mumbai.

Hughes, C., Airey, P., Kluss, T., Tate, P., 2000. Pamphlet Radiotracer Investigations of Sewage Outfall Performance in Hong Kong. ANSTO Environment Division, Sydney.

King, I., 1993. Sydney deep ocean out falls environmental monitoring program post commissioning phase. A Finite element Model for Three Dimensional Density Stratified Flow in AWACS Interim Report 93/01/04, March 1993.

Miller, B.M., Chadwick, M.J., Kluss, T.N., Hughes, C.E., Duran, E.B., 2001. Three dimensional modelling of circulation patterns in Manila Bay, Philippines. Proceedings of the Coasts and Ports Conference, Surfers Paradise, Qld., September 2001, pp. 429-434.

Nielsen, A.F., Kluss, T.N., Hughes, C.E., Sojisuporn, P., Chuienta, S., Adamtidis, C.A., 2001. Field verifications of formulations for sand transport under wave and current 
action. Proceedings of the Coasts and Ports Conference, Surfers Paradise, Qld., September 2001, pp. 481-486.

Pritchard, T.R., Lee, R.S., Davison, A., 1993. Sydney deep ocean outfalls; in-situ observations of plume characteristics. Proceedings of the Eleventh Conference on Coasts and Ocean Engineering, Townsville, pp. 53-58.
Zaw, M., Szymczak, R., Airey, P., 1999. Influence of salinity on the aggregation of sewage particles discharged to a coastal marine environment. Proceedings of the Australian Water and Wastewater Association, 18th Federal Convention, Adelaide, CD ROM. 